\title{
Association of healthy lifestyle score with all-cause mortality and life expectancy: a city-wide prospective cohort study of cancer survivors
}

Ce Sun ${ }^{1+}, \mathrm{Ke} \mathrm{Li}^{2+}$, Huan Xu${ }^{2+}$, Xiangjun Wang ${ }^{1}$, Pengzhe Qin², Suixiang Wang ${ }^{2}$, Boheng Liang ${ }^{2^{*}}$ and Lin Xu ${ }^{1,3^{*}}$

\begin{abstract}
Background: Adherence to a healthy lifestyle could reduce the cancer mortality in the western population. We conducted a city-wide prospective study in China investigating the association of a healthy lifestyle score with all-cause mortality and the life expectancy in cancer survivors.

Methods: This prospective cohort study included 46,120 surviving patients who were firstly diagnosed with cancer in Guangzhou. Five low-risk lifestyle factors including never smoking, never alcohol use, regular physical activity ( $\geq 2 \mathrm{~h} /$ week), sufficient sleep ( $\geq 6 \mathrm{~h} /$ day), and normal or high BMI $\left(\geq 18.5 \mathrm{~kg} / \mathrm{m}^{2}\right.$ ) were assessed and a lifestyle score (0-5, a higher score indicates healthier lifestyle) was generated. Hazard ratios (HRs) of all-cause mortality and the life expectancy by levels of the lifestyle scores were estimated.

Results: Of 46,120 cancer survivors registered from 2010 to 2017, during an average follow-up of 4.3 years (200,285 person-years), 15,209 deaths were recorded. Adjusted HRs for mortality in cancer survivors with lifestyle score of $0-2$, versus 5, were 2.59 (95\% confidence interval (Cl): 2.03-3.30) in women, $1.91(95 \% \mathrm{Cl} 1.77-2.05)$ in men, 2.28 $(95 \% \mathrm{Cl} 2.03-2.55)$ in those aged $<65$ years, and $1.90(95 \% \mathrm{Cl} 1.75,2.05)$ in those aged $\geq 65$ years. Life expectancy at age 55 for those with a score of $0-2$ and 5 was 53.4 and 57.1 months, respectively. We also found that cancer survivors with healthy lifestyle scores of 5 showed 59.9 months of life expectancy on average, which was longer than those with a score of $0-2$.

Conclusion: Adopting a healthy lifestyle was associated with a substantially lower risk of all-cause mortality and longer life expectancy in cancer survivors. Our findings should be useful for health education and health promotion in primary care and clinical practice.
\end{abstract}

Keywords: Healthy lifestyle, Cancer survivor, Mortality, Life expectancy

\footnotetext{
*Correspondence: 14927462@qq.com; linxu@hku.hk

${ }^{\dagger} \mathrm{C}$ S Sun, Ke Li and Huan Xu contributed equally to this work.

${ }^{2}$ Chronic Noncommunicable Disease Prevention and Control Department,

Guangzhou Center for Disease Control and Prevention, No.1 Qide Road,

Baiyun District, Guangzhou 510403, China

${ }^{1}$ School of Public Health, Sun Yat-sen University, Guangzhou 510080, China

Full list of author information is available at the end of the article
}

(c) The Author(s). 2021 Open Access This article is licensed under a Creative Commons Attribution 4.0 International License, which permits use, sharing, adaptation, distribution and reproduction in any medium or format, as long as you give appropriate credit to the original author(s) and the source, provide a link to the Creative Commons licence, and indicate if changes were made. The images or other third party material in this article are included in the article's Creative Commons licence, unless indicated otherwise in a credit line to the material. If material is not included in the article's Creative Commons licence and your intended use is not permitted by statutory regulation or exceeds the permitted use, you will need to obtain permission directly from the copyright holder. To view a copy of this licence, visit http://creativecommons.org/licenses/by/4.0/. The Creative Commons Public Domain Dedication waiver (http://creativecommons.org/publicdomain/zero/1.0/) applies to the data made available in this article, unless otherwise stated in a credit line to the data. 


\section{Background}

China has about one fifth of global cancer cases $[1,2]$. Although cancer survival has overall increased during the past decades [3], people with cancer had a shorter life expectancy than their peers without the disease [4], ranging from 2.4 to 11.2 years, depending on methods and study populations $[4,5]$. Efforts to reduce morbidity and mortality of cancer, such as adherence to a healthy lifestyle, have been advocated in the general population based on published studies [6-9]. For example, previous studies showed that four major unhealthy lifestyle factors (i.e., cigarette smoking, heavy alcohol use, lack of physical activity, and unhealthy diet) contributed to at least $60 \%$ of premature deaths, leading to a loss of 7.417.9 years in life expectancy $[6,10-12]$. However, in cancer survivors, whether adopting a healthy lifestyle will also have similar beneficial effects on life expectancy is unclear.

Hence, our study hereby explored the associations of the individual and combined healthy lifestyle factors with the risk of mortality in cancer survivors, and estimated the association of adherence to healthy lifestyles with life expectancy. Results of this study will facilitate evidence-based tertiary preventive strategies for providing holistic care and improving the quality of life in cancer survivors $[13,14]$.

\section{Methods}

\section{Study design and data collection}

Surviving patients who were firstly diagnosed with cancer from 2010 to 2017 were identified from the Guangzhou Cancer Registry (GCR) of the Guangzhou Center for Disease Control and Prevention (GZCDC) and included in the current study. Information on the diagnosis of cancer was obtained from the electronic medical records in hospitals in Guangzhou. The Guangzhou Cancer Registry was launched in 2008, and the surveillance and follow-up system were established in 2010, which covered residents from all districts of Guangzhou. Data of this study were derived from the GCR. The GCR was approved by the Ministry of Finance of the People's Republic of China, National Health Commission of the People's Republic of China, Guangzhou Municipal Finance Bureau and Guangzhou Municipal Health Commission. Ethical approval of this study was obtained from the ethical committee in the GZCDC.

All types of cancer were included in this study. Local surviving patients who were discharged from local hospitals were referred to primary care centers 1 month after discharge from the hospital and completed a validated brief questionnaire-based survey. Information on demographic characteristics, lifestyle factors including smoking status, alcohol use, physical activity, and sleep duration in the past 30 days, and disease history were collected. Anthropometric measurements such as height and weight were measured. Cancer-related information such as date of diagnosis, diagnosis methods and hospital, types of cancer, and treatment history was derived from medical records. Karnofsky Performance Status (KPS) was used to assess the general functional capacity of the cancer survivors [15].

\section{Lifestyle variables}

Current smoking was defined by at least 1 cigarette/day or 7 cigarettes/week in the past 30 days [16]. Patients were classified as current smokers if they answered "yes, " former smokers if answered "yes in the past, but have quitted smoking now," and non-smokers if answered "no." Besides, alcohol use was defined as the use of alcohol at least $10 \mathrm{~g} /$ day in the past 30 days [17]. Alcohol use was assessed based on the choices of questions about drinking habits and categorized into three groups: never, former, and current alcohol users. Average time spent in physical activity in the past 30 days was also assessed and categorized into four groups: $\leq 1 \mathrm{~h} /$ week, $2-4 \mathrm{~h} /$ week, 5-7 h/week, and $>7 \mathrm{~h} /$ week [18]. Sleep duration was categorized into three groups: $\leq 5 \mathrm{~h} /$ day, $6-8 \mathrm{~h} /$ day, and $\geq 9 \mathrm{~h} /$ day [19]. Body mass index (BMI) was calculated based on measured height and weight and was categorized into four groups according to the National Health Commission of the People's Republic of China: < $18.5 \mathrm{~kg} / \mathrm{m}^{2}, 18.5-23.9 \mathrm{~kg} / \mathrm{m}^{2}, 24.0-27.9 \mathrm{~kg} / \mathrm{m}^{2}$, and $\geq 28.0$ $\mathrm{kg} / \mathrm{m}^{2}[20]$.

\section{Assessment of healthy lifestyle score}

According to previous studies, the healthy lifestyle score was created by combining the most important lifestyle factors relevant to outcome based on a priori knowledge in a binary point system [7-9]. Therefore, a healthy lifestyle score was derived based on five factors associated with cancer mortality, included smoking [21], alcohol use [22], physical activity [23], sleep duration [24], and BMI [25]. Smoking status was categorized into nonsmoking and ever-smoking, and alcohol use was categorized into limited alcohol use and alcohol use. Survivors who reported physical activity of $\geq 2 \mathrm{~h}$ /week were classified as regular physical activity; otherwise, were classified as inactivity. Sleep duration was classified into 2 categories including insufficient sleep ( $\leq 5 \mathrm{~h}$ /day) and sufficient sleep ( $\geq 6 \mathrm{~h} /$ day), and BMI was classified into 2 categories $\left(<18.5 \mathrm{~kg} / \mathrm{m}^{2}\right.$ and $\left.\geq 18.5 \mathrm{~kg} / \mathrm{m}^{2}\right)$. Participants received 1 point for each respective lifestyle factor: nonsmoking, limited alcohol use, regular physical activity, sufficient sleep, or BMI $\geq 18.5 \mathrm{~kg} / \mathrm{m}^{2}$. A combined score $(0-5$ points) was calculated by summing the scores of these 5 factors. We also categorized the score into four groups $(0-2,3,4$, and 5). 


\section{Ascertainment of outcomes}

Outcomes included all-cause mortality in all survivors and by diagnosis. Overall survival was analyzed as the time from diagnosis to death during the follow-up [26]. Information on vital status was collected from the death registration system in the GZCDC. In the present study, we analyzed the mortality data until December 31, 2019.

\section{Statistical analysis}

Person-years of follow-up were calculated from the date of baseline enrollment to death, or the end of the study on December 31, 2019, whichever came first. We used Cox proportional hazards regression models to assess the association of healthy lifestyle score with all-cause mortality risk, giving hazard ratios (HRs) and 95\% confidence intervals (95\% CIs). Potential confounders such as sex, age, education, treatment (surgery, chemotherapy, radiation therapy, traditional Chinese medicine, biotherapy, intervention, and other treatment) and employment status were adjusted. The proportional hazard assumption was tested by the Schoenfeld residuals method [27], and no significant violation of the assumption was found. We also conducted subgroup analyses to examine the potential effect modification by sex and age groups $(<65 / \geq 65$ years). Whether the association was modified by sex and age was assessed by likelihood ratio test comparing models with and without interaction terms. Moreover, we also checked for interactions between the lifestyle score and sex or age by using interaction plots.

We used the life table method to calculate each participant's life expectancy according to different healthy lifestyle scores. The life tables were constructed using three estimates: (1) total number of different healthy lifestyle score in each age group $\left({ }_{n} P_{x}\right)$, (2) the censored number of different healthy lifestyle score in each age group $\left({ }_{n} C_{x}\right)$, and (3) the death toll of different healthy lifestyle score in each age group $\left({ }_{n} D_{x}\right)$. These estimates were used to assess life expectancy for different age intervals using the following methods. Firstly, age-specific all-cause mortality rates $\left({ }_{n} m_{x}\right)$ of different score were calculated as follows [28]: ${ }_{n} m_{x}={ }_{n} D_{x} /\left({ }_{n} P_{x}-{ }_{n} C_{x} / 2\right)$. Secondly, probability of dying was set of 0 at age 55 and set of 1 at more than age 81 . The probability of dying $\left({ }_{n} q_{x}\right)$ between age $t$ and $t+4$ was estimated as [28]: ${ }_{n} q_{x}=$ $2 n \times{ }_{n} m_{x} /\left(2+n \times{ }_{n} m_{x}\right)$, where $n$ refers to the age interval. Thirdly, our study applied the predicted survival probabilities $\left(l_{x}\right)$ on a hypothetical cohort of 100 , 000 55-year-old participants to obtain the expected number of deaths in each age interval $[t, t+4]$ [28]. The number of person-years of survival $\left({ }_{n} L_{x}\right)$ within $[t, t+4]$ was estimated as follows [28]: ${ }_{n} L_{x}=\left(l_{x}+l_{x+n}\right)$ $\times n / 2$. The life expectancy at each age group was then calculated by dividing the total person-years that would be lived beyond age $t$ by the number of persons who survived to that age interval [28].

In sensitivity analyses, we further explored whether the associations varied by sex and age groups in survivors of type-specific cancer (breast cancer, colorectal cancer, lung cancer, liver cancer, nasopharynx cancer, gastric cancer, and kidney cancer). In addition, we conducted leave-one-out analyses excluding single lifestyle factor respectively from the combined healthy lifestyle. We also estimated the association between each lifestyle factor and the life expectancy. As both lifestyle factors and mortality could be influenced by demographic factors (sex, age, education), treatment (surgery, chemotherapy, radiation therapy, traditional Chinese medicine, biotherapy, intervention, and other treatment) and employment [29, 30], these variables were considered as potential confounders. Statistical analysis was done using Stata (STATA Corp LP, version 15). Two-sided $P$ values $<0.05$ were considered as statistically significant.

\section{Results}

Of 47,470 survivors recruited from 2010 to 2017, after excluding those with aged $<18$ years $(n=141)$ and those with missing information on sex $(n=2)$, age $(n=85)$, BMI $(n=1,192)$, smoking status $(n=2)$, and alcohol use $(n=2)$ at baseline, a total of 46,120 cancer survivors (21, 071 men and 25,049 women) were included. The sample selection process was shown in the Additional file 1: Figure $\mathrm{S} 1$.

Of 46,120 cancer survivors, 34.8\%, 47.0\%, 13.2\%, and $5.0 \%$ had a healthy lifestyle score of $5,4,3$, and $0-2$, respectively. Table 1 shows that participants with healthy lifestyle score of 5 were older; had more women; tended to be unemployed; have undergone surgery, chemotherapy, and radiation therap; and had higher BMI and education. They also tended to be never smokers and nonalcohol users, be more physically active, and had longer duration of sleep. Similar patterns were found in survivors of different cancer types (Additional file 2: Tables S1 to S7). Additional file 2: Table S8 shows that most cancer survivors were tended to be never smoking had limited alcohol use, regular physical activity, and sufficient sleeping duration. During an average follow-up of 4.3 years (standard deviation $=2.3$ years; 204,833 personyears), 15,707 deaths were recorded.

Additional file 2: Tables S9 shows that all lifestyle factors were associated with the risk of all-cause mortality. In multivariable Cox regression models, normal (18.5$\left.23.9 \mathrm{~kg} / \mathrm{m}^{2}\right)$ or high $\left(\geq 24.0 \mathrm{~kg} / \mathrm{m}^{2}\right)$ BMI, higher physical activity ( $\geq 2 \mathrm{~h} /$ week), and sleep duration ( $\geq 6 \mathrm{~h} /$ day) were significantly associated with a lower risk of mortality in cancer survivors. Compared with never smoking, 
Table 1 Baseline characteristics by Healthy Lifestyle Score in 46,120 cancer survivors

\begin{tabular}{|c|c|c|c|c|c|}
\hline & \multicolumn{4}{|c|}{ Healthy Lifestyle Score } & \multirow[t]{2}{*}{$P$ value } \\
\hline & $0-2$ & 3 & 4 & 5 & \\
\hline \multicolumn{6}{|l|}{ Sex, N (\%) } \\
\hline Women & $126(5.5)$ & $1705(28.0)$ & $12,809(59.1)$ & $10,404(64.8)$ & \multirow[t]{2}{*}{$<0.001$} \\
\hline Men & $2174(94.5)$ & $4377(72.0)$ & $8866(40.9)$ & $5659(35.2)$ & \\
\hline \multicolumn{6}{|l|}{ Age, years, N (\%) } \\
\hline$<65$ & $938(40.8)$ & 2495 (41.1) & $10,475(48.4)$ & 8105 (50.6) & \multirow[t]{2}{*}{$<0.001$} \\
\hline$\geq 65$ & $1359(59.2)$ & $3578(58.9)$ & $11,162(51.6)$ & 7927 (49.4) & \\
\hline \multicolumn{6}{|l|}{ Education, N (\%) } \\
\hline Primary or below & $994(43.2)$ & $2364(38.9)$ & $7874(36.3)$ & $5183(32.3)$ & \multirow[t]{2}{*}{$<0.001$} \\
\hline Secondary or above & $1306(56.8)$ & $3718(61.1)$ & $13,801(63.7)$ & $10,880(67.7)$ & \\
\hline \multicolumn{6}{|l|}{ Employment, N (\%) } \\
\hline Unemployed & $1619(70.5)$ & $4630(76.5)$ & $16,570(77.2)$ & $11,932(74.7)$ & \multirow[t]{2}{*}{0.001} \\
\hline Employed & $677(29.5)$ & $1424(23.5)$ & $4899(22.8)$ & $4038(25.3)$ & \\
\hline \multicolumn{6}{|l|}{ Treatment, N (\%) } \\
\hline Surgery & $1176(51.1)$ & $3530(58.0)$ & $14,554(67.2)$ & $11763(73.2)$ & $<0.001$ \\
\hline Chemotherapy & $629(27.4)$ & 1695 (27.9) & $6132(28.3)$ & $4495(28.0)$ & $<0.001$ \\
\hline Radiation therapy & $468(20.4)$ & $1244(20.5)$ & $4599(21.2)$ & $3454(21.5)$ & $<0.001$ \\
\hline Traditional Chinese medicine & $149(6.5)$ & $516(8.5)$ & $1523(7.0)$ & $1235(7.7)$ & $<0.001$ \\
\hline Biotherapy & $7(0.3)$ & $20(0.3)$ & $44(0.2)$ & $26(0.2)$ & $<0.001$ \\
\hline Intervention & $84(3.7)$ & $172(2.8)$ & $453(2.1)$ & $265(1.7)$ & $<0.001$ \\
\hline Other & $908(39.5)$ & $2172(35.7)$ & $6364(29.4)$ & $4094(25.5)$ & $<0.001$ \\
\hline \multicolumn{6}{|l|}{$\mathrm{BMI}, \mathrm{kg} / \mathrm{m}^{2}, \mathrm{~N}(\%)$} \\
\hline$<18.5$ & $553(24.0)$ & $1913(31.5)$ & $1245(5.7)$ & $0(0.0)$ & \\
\hline $18.5-23.9$ & $1340(58.3)$ & $3195(52.5)$ & $15,734(72.6)$ & $11,852(73.8)$ & \\
\hline $23-27.9$ & $353(15.4)$ & $845(13.9)$ & $4090(18.9)$ & 3609 (22.5) & \\
\hline$\geq 28.0$ & $54(2.4)$ & $129(2.1)$ & $606(2.8)$ & $602(3.8)$ & $<0.001$ \\
\hline \multicolumn{6}{|l|}{ Smoking status, N (\%) } \\
\hline Never & $178(7.7)$ & $2849(37.2)$ & $20,149(93.0)$ & $16,063(100.0)$ & \\
\hline Former & $650(28.3)$ & $1463(24.1)$ & 849 (3.9) & $0(0.0)$ & \\
\hline Current & $1472(64.0)$ & $1770(29.1)$ & $677(3.1)$ & $0(0.0)$ & $<0.001$ \\
\hline \multicolumn{6}{|l|}{ Alcohol use, N (\%) } \\
\hline Never & $426(18.5)$ & $4670(76.8)$ & $21,230(98.0)$ & $16,063(100.0)$ & \multirow[t]{2}{*}{$<0.001$} \\
\hline Ever & $1874(81.5)$ & $1412(23.2)$ & $445(2.1)$ & $0(0.0)$ & \\
\hline \multicolumn{6}{|l|}{ Physical activity, hours/week, N (\%) } \\
\hline$\leq 1$ & $2213(96.2)$ & $5049(83.0)$ & $18,152(83.8$ & $0(0.0)$ & \\
\hline $2-4$ & $75(3.3)$ & $849(14.0)$ & $2886(13.3)$ & $13,364(83.2)$ & \\
\hline $5-7$ & $12(0.5)$ & $159(2.6)$ & $558(2.6)$ & $2461(15.3)$ & \\
\hline$>7$ & $0(0.0)$ & $25(0.4)$ & $79(0.4)$ & $238(1.5)$ & $<0.001$ \\
\hline \multicolumn{6}{|l|}{ Sleep duration, hours/day, N (\%) } \\
\hline$\leq 5$ & $389(16.9)$ & $557(9.2)$ & $307(1.4)$ & $0(0.0)$ & \multirow[t]{3}{*}{$<0.001$} \\
\hline $6-8$ & $1857(80.7)$ & $5330(87.6)$ & $20,563(94.9)$ & $15,247(94.9)$ & \\
\hline$\geq 9$ & $54(2.4)$ & $195(3.2)$ & 805 (3.7) & $816(5.1)$ & \\
\hline
\end{tabular}

Abbreviation: $N$ number, $B M I$ body mass index 
Table 2 Adjusted hazards ratios (HRs) and 95\% confidence interval (Cls) of mortality related to Five Healthy Lifestyle Index in cancer survivors stratified by sex and age groups

\begin{tabular}{|c|c|c|c|c|c|}
\hline & \multicolumn{4}{|c|}{ Healthy Lifestyle Score } & \multirow{2}{*}{$\begin{array}{l}P \text { for } \\
\text { interaction }\end{array}$} \\
\hline & $0-2$ & 3 & 4 & 5 & \\
\hline Total & $2.02(1.89,2.16)^{* * *}$ & $1.66(1.58,1.75)^{* * *}$ & $1.37(1.31,1.42)^{* * *}$ & $\operatorname{Ref}(1.00)$ & \\
\hline \multicolumn{6}{|l|}{ Sex } \\
\hline Women & $2.59(2.03,3.30)^{* * *}$ & $1.81(1.66,2.00)^{* * *}$ & $1.42(1.35,1.51)^{* * *}$ & $\operatorname{Ref}(1.00)$ & \\
\hline Men & $1.91(1.77,2.05)^{* * *}$ & $1.56(1.47,1.66)^{* * *}$ & $1.29(1.22,1.37)^{* * *}$ & $\operatorname{Ref}(1.00)$ & $<0.01$ \\
\hline \multicolumn{6}{|l|}{ Age, years } \\
\hline$<65$ & $2.28(2.03,2.55)^{* * *}$ & $1.75(1.60,1.92)^{* * *}$ & $1.39(1.29,1.49)^{* * *}$ & $\operatorname{Ref}(1.00)$ & \\
\hline$\geq 65$ & $1.90(1.75,2.05)^{* * *}$ & $1.63(1.53,1.73)^{* * *}$ & $1.35(1.29,1.42)^{* * *}$ & $\operatorname{Ref}(1.00)$ & $<0.01$ \\
\hline
\end{tabular}

Adjusted for sex, age, education, treatment (surgery, chemotherapy, radiation therapy, traditional Chinese medicine, biotherapy, intervention, other treatments), and employment except the corresponding subgroup variable. ${ }^{*} P<0.05$, ${ }^{*} P<0.01$, and ${ }^{* *} P<0.001$

former and current smoking were significantly associated with a higher risk of mortality (HR 1.83, 95\% CI 1.73 to 1.93 , and HR $1.67,95 \%$ CI 1.58 to 1.77 , respectively). Alcohol users also showed a significantly higher risk of all-cause mortality (HR 1.09, 95\% CI 1.03 to 1.16). When stratifying by types of cancer, normal to high BMI, higher physical activity, and sufficient sleep duration were significantly associated with a lower risk of death in survivors of most cancer types (breast cancer, colorectal cancer, lung cancer, liver cancer, nasopharynx cancer, and gastric cancer) (Additional file 2: Tables S10-S15), and current smoking was associated with a higher risk of death in colorectal cancer survivors. Normal to high BMI and higher physical activity were significantly associated with a lower risk of death in kidney cancer (Additional file 2: Table S16).

For all cancer survivors, the associations with risk of mortality were more pronounced in women than men (Additional file 3: Figure S2B). Compared with the healthy lifestyle score of 5 , female and male survivors with a score of $0-2$ had a higher risk of mortality, with the adjusted HR $(95 \% \mathrm{CI})$ being $2.59(2.03,3.30)$ and $1.91(1.77,2.05)$, respectively. We also found that the associations varied by age groups (Additional file 3: Figure S2C), with the adjusted HR (95\% CI) for a score of 0-2 being $2.28(2.03,2.55)$ in younger $(<65$ years) and 1.90 $(1.75,2.05)$ in older ( $\geq 65$ years) group (Table 2$)$.

Similar findings were found when stratifying by types of cancer. However, for survivors of most cancer types except breast cancer, colorectal cancer, and nasopharynx cancer, mortality risk was more pronounced in men (Additional file 2: Tables S17-S23). We also found that the associations were more pronounced in younger age groups in survivors of breast, liver, nasopharynx, gastric, and kidney cancer, but not varied by sex in colorectal cancer and lung cancer survivors (Additional file 4: Figure S3A-S3U).

Figure 1 shows that, for those with a score of $0-2,3$, 4 , and 5, the life expectancy at age 55 was 53.4, 55.2, 56.1, and 57.1 months, respectively. Sensitivity analyses

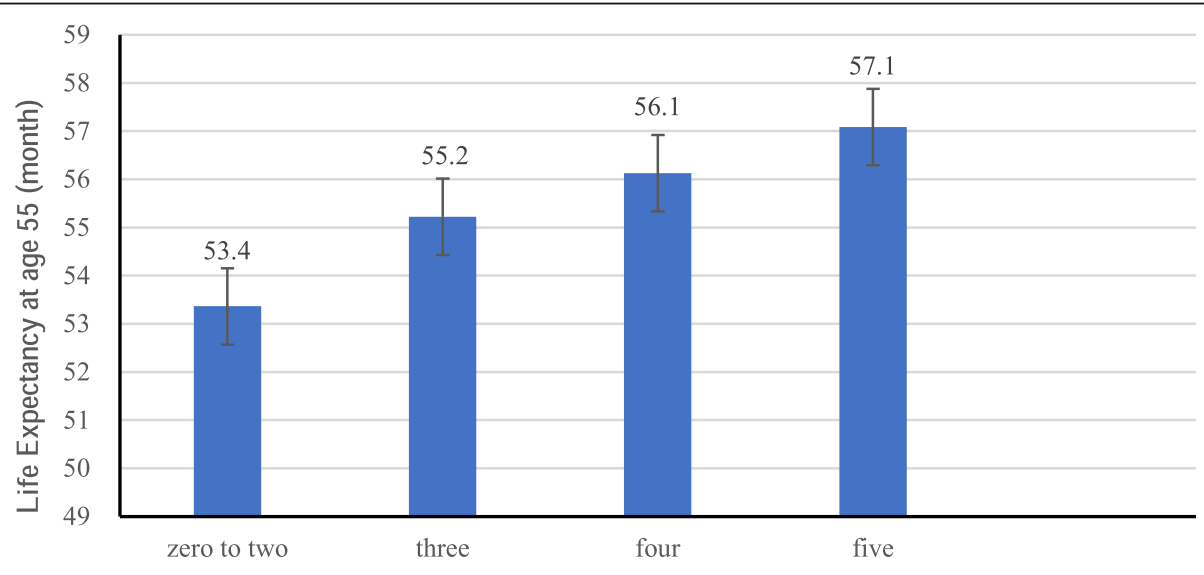

Number of low-risk lifestyle factors

Fig. 1 Estimated life expectancy at age 55 according to the number of low-risk lifestyle factors. Low-risk lifestyle factors included never smoking status, never alcohol use, high levels of physical activity ( $\geq 2 \mathrm{~h} /$ week), longer sleep duration ( $\geq 6 \mathrm{~h} /$ day) and normal BMl $\left(\geq 18.5 \mathrm{~kg} / \mathrm{m}^{2}\right.$ ) 
a Estimated life expectancy at age 55 according to the number of low-risk lifestyle factors excluding smoking status.
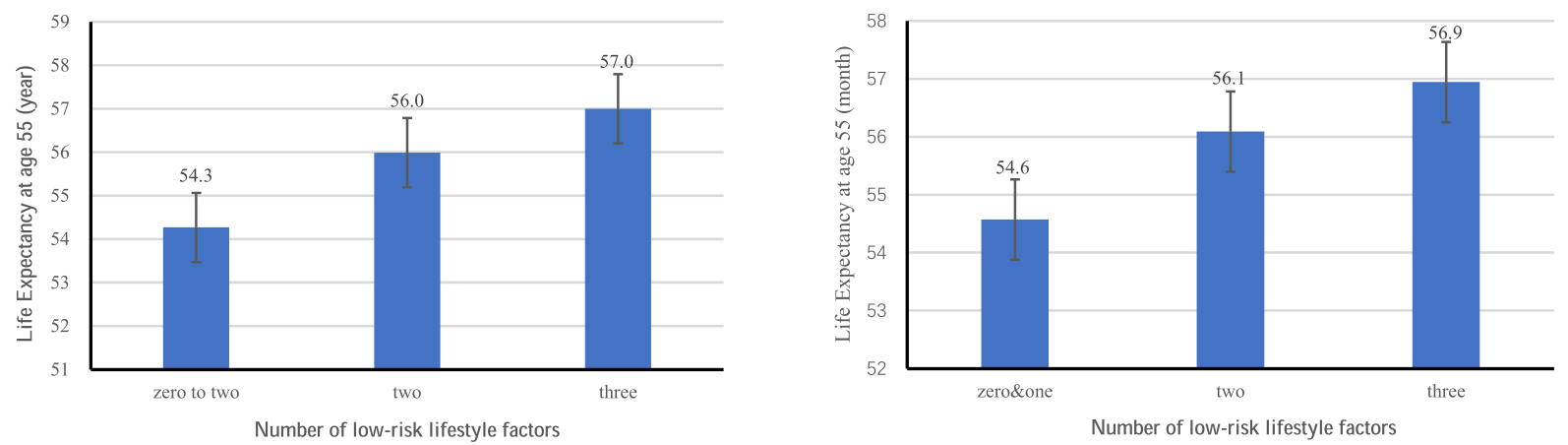

b Estimated life expectancy at age 55 according to the number of low-risk lifestyle factors excluding alcohol use
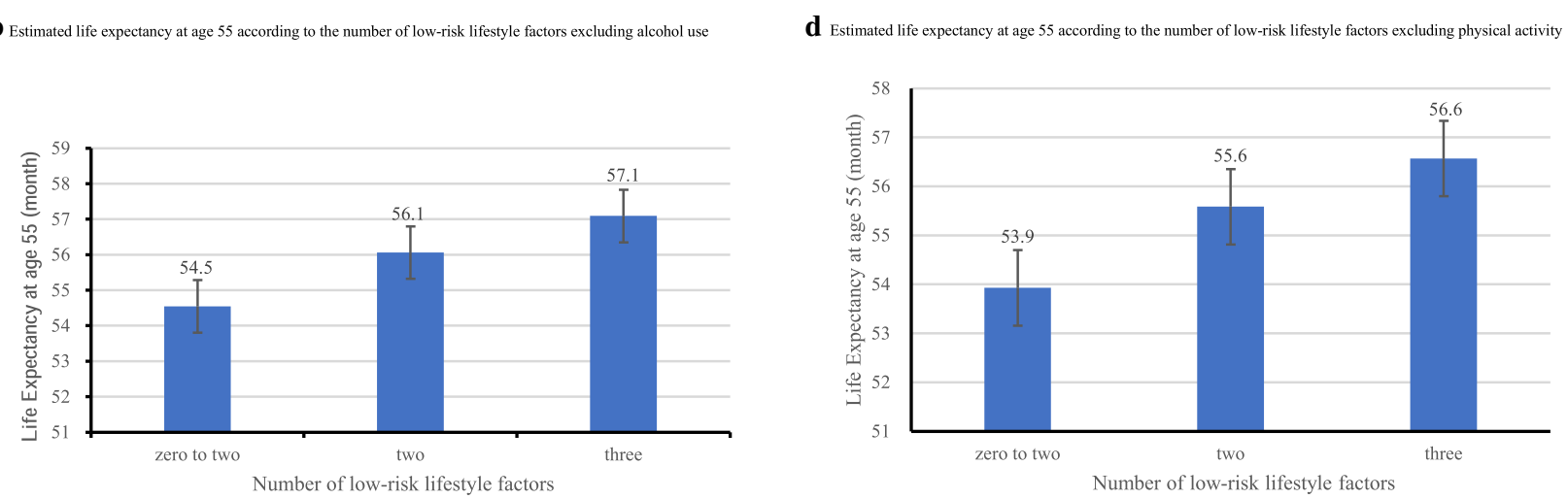

Cstimated life expectancy at age 55 according to the number of low-risk lifestyle factors excluding BMI

e Estimated life expectancy at age 55 according to the number of low-risk lifestyle factors excluding sleep duration

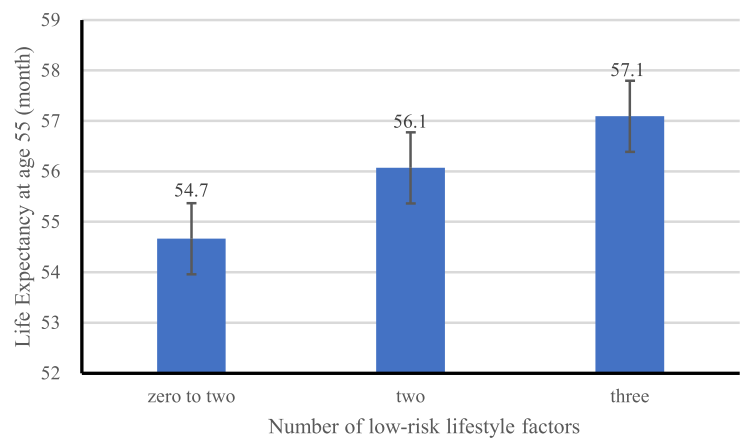

Fig. 2 Estimated life expectancy at age 55 according to the number of low-risk lifestyle factors excluding individual low-risk lifestyle factors (excluding a smoking status, $\mathbf{b}$ alcohol use, c physical activity, $\mathbf{d}$ sleep, e body mass index). Low-risk lifestyle factors included never smoking status, never alcohol use, regular physical activity ( $\geq 2 \mathrm{~h} /$ week), sufficient sleep duration ( $\geq 6 \mathrm{~h} /$ day) and normal BMl $\left(\geq 18.5 \mathrm{~kg} / \mathrm{m}^{2}\right)$

using leave-one-out showed similar results (Fig. 2a-e). Moreover, Fig. 3 shows that cancer survivors with a score of 5 had a life expectancy of 59.9 (95\% CI 59.5 to $60.3)$ months on average, which was substantially longer than those with a score of $0-2$ (46.2 months on average, 95\% CI 45.3 to 47.1 ). The positive associations between scores and life expectancy were consistent across different age groups (Fig. 3).

Figures 4 shows the life expectancy by each lifestyle factor. Never smoking (Fig. 4a), never alcohol use (Fig. 4b), higher levels of physical activity (Fig. 4c), sufficient sleep duration (Fig. 4d), and normal BMI (Fig. 4e) were associated with a longer life expectancy. In addition, we found that cancer survivors with alcohol use and smoking had a shorter life expectancy. The average life expectancy in smokers was 47.7 months (95\% CI: 47.5 to 47.9 ), which was lower than never smokers (55.6 months, 95\% CI: 55.4 to 55.9) (Fig. 4a). Similar patterns were found for alcohol use, with the average life expectancy 


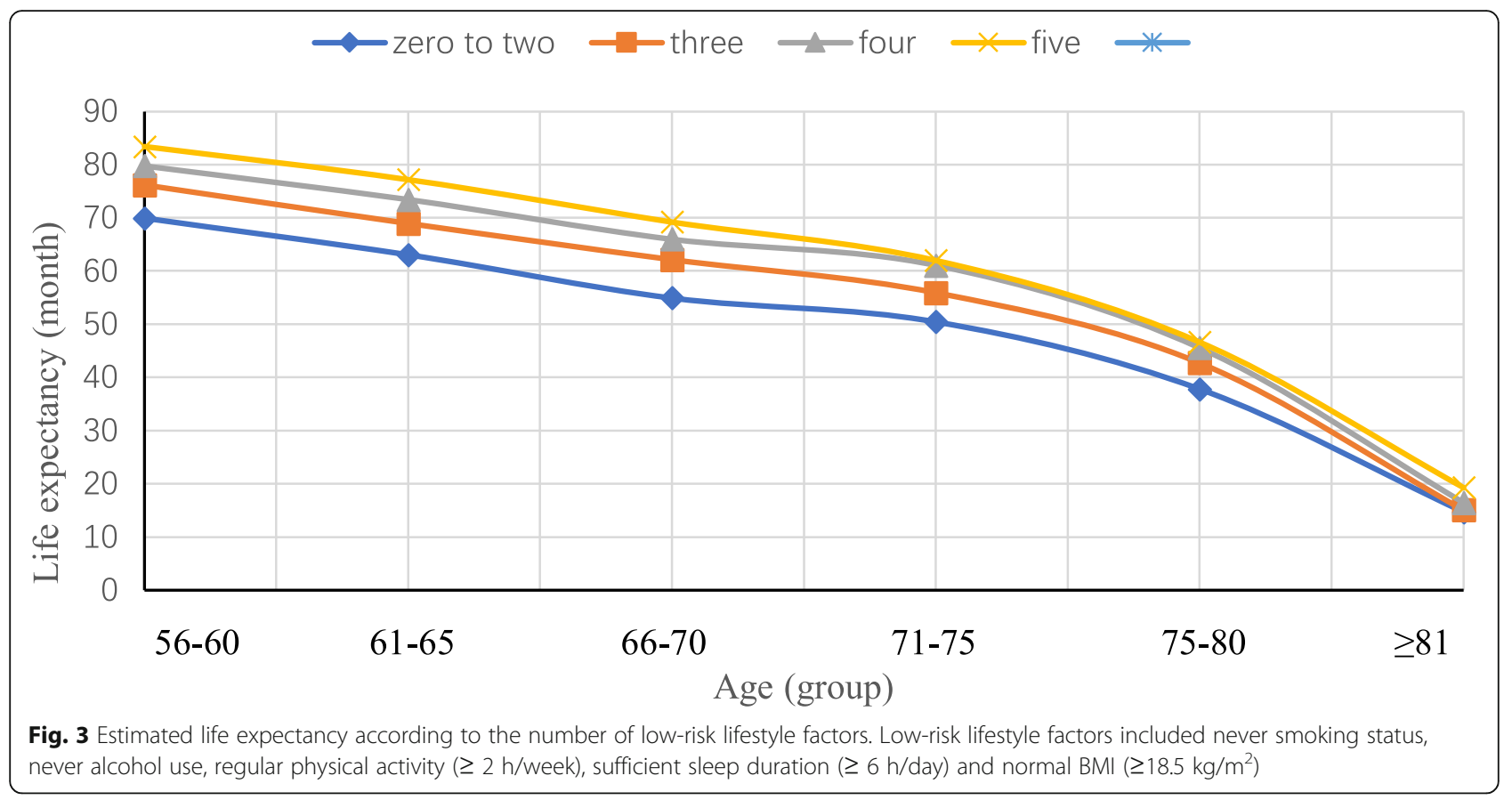

being 47.4 (95\% CI 46.5 to 48.3 ) months for alcohol users and 54.9 (95\% CI 54.7 to 55.2) months for never alcohol users (Fig. 4b).

\section{Discussion}

In this study of near fifth thousand cancer survivors in China, all defined healthy lifestyle factors were independently associated with a lower risk of all-cause mortality. Survivors with cancer or different types of cancer who adopted healthy lifestyle behaviors had significantly lower risks of death. Furthermore, our results also indicate that cancer survivors can gain an average of about 4 months life expectancy at age 55 by adopting a healthy lifestyle, which should be important in primary care settings to promote healthy lifestyles.

Our results are generally consistent with previous studies from the western settings [7, 8, 31, 32]. Although lifestyle factors included in each study were slightly different, results of all studies consistently showed beneficial effects on all-cause mortality by adopting healthy lifestyles. The Nurses' Health Study (NHS) and Health Professions Follow-up Study (HPFS) showed that adherence to never smoking, regular physical activity and healthy diet, and maintenance of a normal weight were associated with a lower risk of cancer mortality and a longer life expectancy [7, 8]. A large study in Europe found that of participants without chronic diseases (cardiovascular disease, cancer, respiratory disease, and diabetes), those with at least 2 high-risk factors (smoking, physical inactivity, and obesity) had a shorter life expectancy by 6 years compared to those without any of these three risk factors [31]. In the EPICHeidelberg cohort in Germany, healthy lifestyles (i.e., no smoking, healthier BMI, no-to-low alcohol use, and low processed/red meat consumption) were associated with a longer life expectancy by 17.0 years in men and 13.9 years in women at age 40 [32]. Furthermore, the Singapore Chinese Health Study also found that adherence to 4-5 healthy lifestyle factors, relative to those without any healthy lifestyle factors, showed a longer life expectancy by 8.1 years in women and 6.6 years in men at age 50 [9]. All the studies above were conducted in the general populations. However, evidence concerning the association of adopting healthy lifestyles with the risk of mortality and life expectancy in cancer survivors were scarce. Our results for the first time showed that even in cancer survivors, adherence to healthier lifestyle behaviors still exerts beneficial effects and needs to be encouraged. Hence, our results may provide important supplementary evidence to be used in clinical practice.

Previous studies showed that overweight and obesity were associated with a higher risk of cancer in the general population [33]. However, our study found that higher BMI was a protective factor in cancer survivors. Recent studies showed that cancer patients with lower BMI had a higher risk of mortality than patients with obesity [34, 35]. A review also showed that obesity was associated with a lower risk of 
a Estimated life expectancy according to smoking status

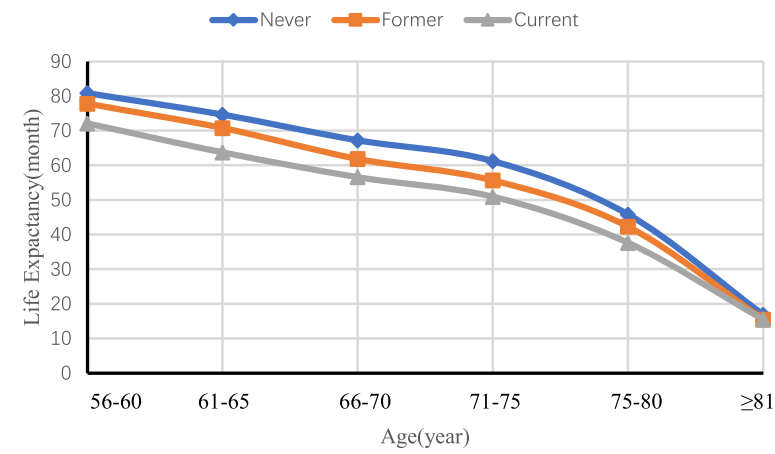

b Estimated life expectancy according to alcohol use

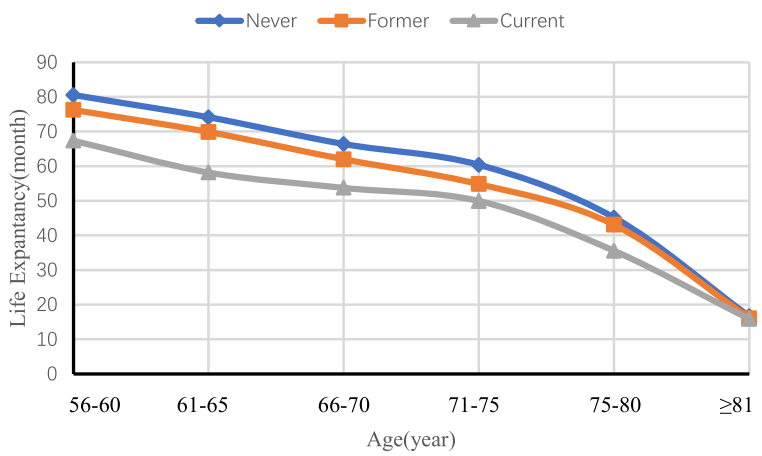

c Estimated life expectancy according to physical activity

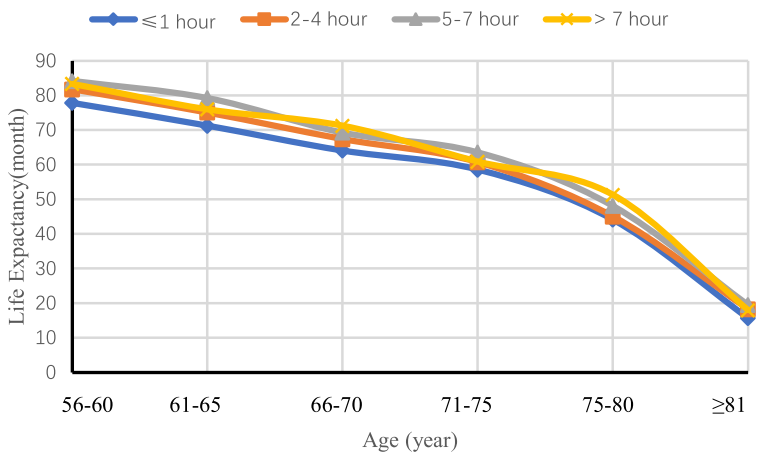

d Estimated life expectancy according to sleep

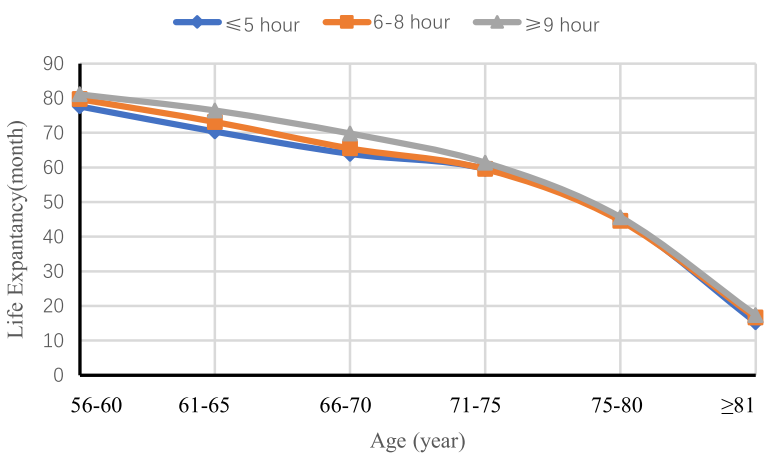

c Estimated life expectancy according to BMI groups

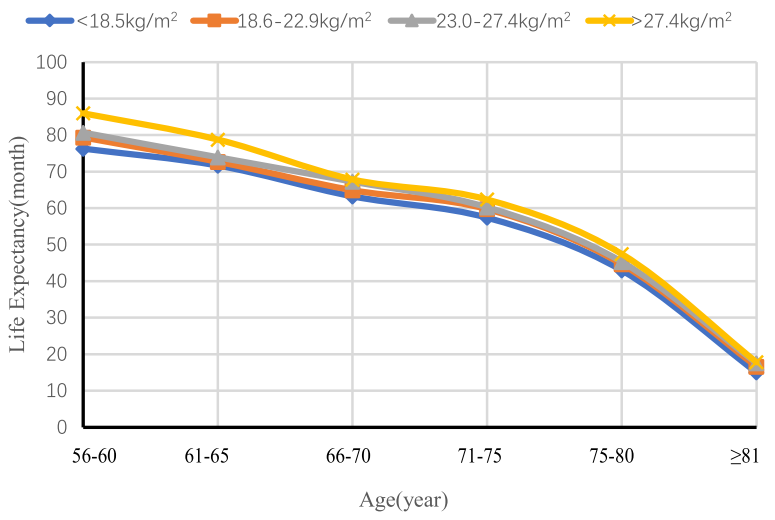

Fig. 4 Estimated life expectancy according to individual low-risk lifestyle factors (a smoking status, b alcohol use, c physical activity, d sleep, e body mass index). Low-risk lifestyle factors included never smoking status, never alcohol use, regular physical activity ( $\geq 2$ h/week), sufficient sleep duration ( $\geq 6 \mathrm{~h} /$ day) and normal BMl $\left(\geq 18.5 \mathrm{~kg} / \mathrm{m}^{2}\right)$

mortality in cancer patients, suggesting an existence of 'obesity paradox' [36]. However, as most of the cancer survivors in our study had a normal BMI $\left(18.5-23.9 \mathrm{~kg} / \mathrm{m}^{2}\right)$, whether obesity plays a role in the prognosis of cancer survivors warrants further investigation. Moreover, it is worth mentioning that lightto-moderate alcohol consumption was shown as protective in the general population [7-9]. We found that alcohol use was not associated with mortality risk in colorectal cancer survivors, which was consistent with a previous meta-analysis [37]. However, our study found that alcohol use was significantly associated with higher risk of all-cause mortality and lower life expectancy in cancer survivors. Hence, our results support that there is no safe limit for alcohol intake in most cancer survivors [38]. 
Our study has some strengths and limitations. Strengthens of our study include its longitudinal study design, large sample size, and city-wide representative sample of cancer survivors. There are also some limitations to be considered and discussed. First, information of the lifestyle factors was collected via self-reports using simple questions. Thus, details of each lifestyle factors, such as types of alcohol used and physical activity were not assessed. However, using simple questions might reduce misclassification of exposures and could facilitate further public health information translation. Second, lifestyle factors were measured at baseline and some factors might have changed during the follow-up, which, if any, tends to bias the results towards the null. Third, as other traditional observational cohort studies, residual confounding due to unmeasured or unknown factors could not be ruled out. Fourth, as most cancer epidemiologic studies, information of stages of cancer and duration from disease onset to diagnosis was unavailable. Fifth, as all cancer patients were from Guangzhou, China, our results might not be directly applicable to other settings or ethnicities. Finally, we did not include diet in the lifestyle score. However, because dietary patterns varied greatly across settings, and there is no consensus on the definition of a healthy diet pattern in cancer survivors $[7,8]$, further studies exploring healthy dietary patterns in site specific cancer survivors are also needed.

\section{Conclusions}

In summary, adopting a healthy lifestyle was associated with a substantially lower risk of all-cause mortality and longer life expectancy in cancer survivors. Our findings should be useful for health education and health promotion in primary care and clinical practice.

\section{Abbreviations \\ BMI: Body mass index; Cl: Confidence interval; GZCDC: Guangzhou Cancer Registry of the Guangzhou Center for Disease Control and Prevention; GCR: Guangzhou Cancer Registry; HPFS: Health Professions Follow-up Study; HRs: Hazard radios; KPS: Karnofsky Performance Status; NHS: Nurses' Health Study}

\section{Supplementary Information}

The online version contains supplementary material available at https://doi. org/10.1186/s12916-021-02024-2

Additional file 1: Figure S1. Study sample selection.

Additional file 2: Table S1. Baseline characteristics of 7,065 breast cancer survivors by healthy lifestyle score. Table S2. Baseline characteristics of 6,870 colorectal cancer survivors by healthy lifestyle score. Table S3. Baseline characteristics of 5,542 lung cancer survivors by healthy lifestyle score. Table S4. Baseline characteristics of 2,713 liver cancer survivors by healthy lifestyle score. Table S5. Baseline characteristics of 2,545 nasopharynx cancer survivors by healthy lifestyle score. Table S6. Baseline characteristics of 1,421 gastric cancer survivors by healthy lifestyle score. Table S7. Baseline characteristics of 731 kidney cancer survivors by healthy lifestyle score. Table S8. Distribution of cancer diagnosis by lifestyle index. Table S9. Criteria for determining the healthy lifestyle factors in all cancer survivors. Table S10. Criteria for determining the healthy lifestyle factors in breast cancer survivors. Table S11. Criteria for determining the healthy lifestyle factors in colorectal cancer survivors. Table S12. Criteria for determining the healthy lifestyle factors in lung cancer survivors. Table S13. Criteria for determining the healthy lifestyle factors in liver cancer survivors. Table S14. Criteria for determining the healthy lifestyle factors in nasopharynx cancer survivors. Table S15. Criteria for determining the healthy lifestyle factors in gastric cancer survivors. Table S16. Criteria for determining the healthy lifestyle factors in kidney cancer survivors. Table S17. Adjusted hazards ratios (HRs) and 95\% confidence intervals (Cls) of mortality related to five healthy lifestyle index in breast cancer survivors by sex and age groups. Table S18. Adjusted hazards ratios (HRs) and 95\% confidence intervals (Cls) of mortality related to five healthy lifestyle index in colorectal cancer survivors by sex and age groups. Table S19. Adjusted hazards ratios (HRs) and 95\% confidence intervals (Cls) of mortality related to five healthy lifestyle index in lung cancer survivors by sex and age groups. Table S20. Adjusted hazards ratios (HRs) and 95\% confidence intervals (Cls) of mortality related to five healthy lifestyle index in liver cancer survivors by sex and age groups. Table S21. Adjusted hazards ratios (HRs) and 95\% confidence intervals (Cls) of mortality related to five healthy lifestyle index in nasopharynx cancer survivors by sex and age groups. Table S22. Adjusted hazards ratios (HRs) and 95\% confidence intervals (Cls) of mortality related to five healthy lifestyle index in gastric cancer survivors by sex and age groups. Table S23. Adjusted hazards ratios (HRs) and 95\% confidence intervals (Cls) of mortality related to five healthy lifestyle index in kidney cancer survivors by sex and age groups.

Additional file 3: Figure S2. Estimation of mortality risks with or without interaction term in all cancer survivors. (A: without interaction term, B: with interaction term by sex, C: with interaction term by age).

Additional file 4: Figure S3. Estimation of mortality risks with or without interaction term in cancer- specific survivors. (A: without interaction term in breast cancer, B: with interaction term in breast cancer by sex, C: with interaction term in breast cancer by age, D: without interaction term in colorectal cancer, $\mathrm{E}$ : with interaction term in colorectal cancer by sex, $\mathrm{F}$ : with interaction term in colorectal cancer by age, G: without interaction term in lung cancer, $\mathrm{H}$ : with interaction term in lung cancer by sex, l: with interaction term in lung cancer by age, J: without interaction term in liver cancer, $\mathrm{K}$ : with interaction term in liver cancer by sex, L: with interaction term in liver cancer by age, $M$ : without interaction term in nasopharynx cancer, $\mathrm{N}$ : with interaction term in nasopharynx cancer by sex, O: with interaction term in nasopharynx cancer by age, $\mathrm{P}$ : without interaction term in gastric cancer, Q: with interaction term in gastric cancer by sex, $R$ : with interaction term in gastric cancer by age, $\mathrm{S}$ : with interaction term in nasopharynx cancer by age, $\mathrm{T}$ : without interaction term in kidney cancer, $\mathrm{U}$ : with interaction term in kidney cancer by sex, $\mathrm{V}$ : with interaction term in kidney cancer by age).

Additional file 5. STROBE Statement-Checklist of items that should be included in reports of cohort studies.

\section{Acknowledgements}

Not applicable.

\section{Authors' contributions}

$\mathrm{CS}, \mathrm{KL}$, and $\mathrm{HX}$ contributed to the design of study, conducted study, and drafted the initial manuscript. $\mathrm{LX}$ and $\mathrm{BHL}$ contributed to the idea and design of this study and revised manuscript. CS, XJW, and SXW assisted in analyzing the data and interpreting the data. The authors read and approved the final manuscript.

\section{Funding}

This work was funded by the Natural Natural Science Foundation of China (No. 81941019) and the Major Infectious Disease Prevention and Control of the National Science and Technique Major Project (No. 2018ZX10715004).

\section{Availability of data and materials}

The datasets used and analyzed during the current study are available from the corresponding author on reasonable request. 


\section{Declarations}

\section{Ethics approval and consent to participate}

This study has been approved by the Guangzhou Municipal Health Commission. Ethical approval of this study was obtained from the ethical committee in the Guangzhou Center for Disease Control and Prevention. The informed consent was given by all participants to data collection and individual follow-up.

\section{Consent for publication}

Not applicable.

\section{Competing interests}

The authors declare that they have no competing interests.

\section{Author details}

${ }^{1}$ School of Public Health, Sun Yat-sen University, Guangzhou 510080, China. ${ }^{2}$ Chronic Noncommunicable Disease Prevention and Control Department, Guangzhou Center for Disease Control and Prevention, No.1 Qide Road, Baiyun District, Guangzhou 510403, China. ${ }^{3}$ School of Public Health, University of Hong Kong, Hong Kong, China.

Received: 8 January 2021 Accepted: 3 June 2021

Published online: 07 July 2021

\section{References}

1. Torre LA, Bray F, Siegel RL, Ferlay J, Lortet-Tieulent J, Jemal A. Global cancer statistics, 2012. CA Cancer J Clin. 2015;65(2):87-108. https://doi.org/10.3322/ caac. 21262.

2. Ferlay J, Soerjomataram I, Dikshit R, Eser S, Mathers C, Rebelo M, et al. Cancer incidence and mortality worldwide: sources, methods and major patterns in GLOBOCAN 2012. Int J Cancer. 2015;136(5):E359-86. https://doi. org/10.1002/ijc.29210.

3. Zeng H, Chen W, Zheng R, Zhang S, Ji JS, Zou X, et al. Changing cancer survival in China during 2003-15: a pooled analysis of 17 population-based cancer registries. Lancet Glob Health. 2018;6(5):e555-67. https://doi.org/10.1 016/S2214-109X(18)30127-X.

4. Capocaccia R, Gatta G, Dal Maso L. Life expectancy of colon, breast, and testicular cancer patients: an analysis of US-SEER population-based data. Ann Oncol. 2015;26(6):1263-8. https://doi.org/10.1093/annonc/mdv131.

5. Andersson TM, Dickman PW, Eloranta S, Lambe M, Lambert PC. Estimating the loss in expectation of life due to cancer using flexible parametric survival models. Stat Med. 2013;32(30):5286-300. https://doi.org/10.1002/sim. 5943.

6. Loef $\mathrm{M}$, Walach $\mathrm{H}$. The combined effects of healthy lifestyle behaviors on all cause mortality: a systematic review and meta-analysis. Prev Med. 2012; 55(3):163-70. https://doi.org/10.1016/j.ypmed.2012.06.017.

7. Li Y, Schoufour J, Wang DD, Dhana K, Pan A, Liu X, et al. Healthy lifestyle and life expectancy free of cancer, cardiovascular disease, and type 2 diabetes: prospective cohort study. BMJ. 2020;368:16669.

8. Li Y, Pan A, Wang DD, Liu X, Dhana K, Franco OH, et al. Impact of healthy lifestyle factors on life expectancies in the US population. Circulation. 2018; 138(4):345-55. https://doi.org/10.1161/CIRCULATIONAHA.117.032047.

9. Pan XF, Li Y, Franco OH, Yuan JM, Pan A, Koh WP. Impact of combined lifestyle factors on all-cause and cause-specific mortality and life expectancy in Chinese: the Singapore Chinese Health Study. J Gerontol A Biol Sci Med Sci. 2019;(11):2193-9. https://doi.org/10.1093/gerona/glz271.

10. Mokdad AH, Forouzanfar MH, Daoud F, Mokdad AA, El BC, Moradi-Lakeh M, et al. Global burden of diseases, injuries, and risk factors for young people's health during 1990-2013: a systematic analysis for the Global Burden of Disease Study 2013. Lancet. 2016;387(10036):2383-401. https://doi.org/10.1 016/S0140-6736(16)00648-6.

11. Manuel DG, Perez R, Sanmartin C, Taljaard M, Hennessy D, Wilson K, et al. Measuring burden of unhealthy behaviours using a multivariable predictive approach: life expectancy lost in Canada attributable to smoking, alcohol, physical inactivity, and diet. PLoS med. 2016;13(8):e1002082. https://doi. org/10.1371/journal.pmed.1002082.

12. O'Doherty MG, Cairns K, O'Neill V, Lamrock F, Jørgensen T, Brenner $\mathrm{H}$, et al. Effect of major lifestyle risk factors, independent and jointly, on life expectancy with and without cardiovascular disease: results from the Consortium on Health and Ageing Network of Cohorts in Europe and the
United States (CHANCES). Eur J Epidemiol. 2016;31(5):455-68. https://doi. org/10.1007/s10654-015-0112-8.

13. Brenner $\mathrm{H}$, Chen $\mathrm{C}$. The colorectal cancer epidemic: challenges and opportunities for primary, secondary and tertiary prevention. Br J Cancer. 2018;119(7):785-92. https://doi.org/10.1038/s41416-018-0264-x.

14. Torre LA, Siegel RL, Ward EM, Jemal A. Global cancer incidence and mortality rates and trends--an update. Cancer Epidemiol Biomarkers Prev. 2016;25(1):16-27. https://doi.org/10.1158/1055-9965.EPI-15-0578.

15. Friendlander AH, Ettinger RL. Karnofsky performance status scale. Spec Care Dentist. 2009;29(4):147-8. https://doi.org/10.1111/j.1754-4505.2009.00088.x.

16. World Health Organization: Guidelines for controlling and monitoring the tobacco epidemic: guidelines for controlling and monitoring the tobacco epidemic; 1998.

17. World Health Organization. International guide for monitoring alcohol consumption and related harm. Geneva: WHO; 2000

18. Rock CL, Doyle C, Demark-Wahnefried W, Meyerhardt J, Courneya KS, Schwartz AL, et al. Nutrition and physical activity guidelines for cancer survivors. CA Cancer J Clin. 2012;62(4):243-74. https://doi.org/10.3322/caa C.21142.

19. Saper CB, Fuller PM, Pedersen NP, Lu J, Scammell TE. Sleep state switching. Neuron. 2010;68(6):1023-42. https://doi.org/10.1016/j.neuron.2 010.11.032.

20. National Health Commission of the People's Republic of China. Criteria of weight for adults (WS/T 428-2013). Beijing: Standards Press of China; 2013.

21. Islami F, Goding SA, Miller KD, Siegel RL, Fedewa SA, Jacobs EJ, et al. Proportion and number of cancer cases and deaths attributable to potentially modifiable risk factors in the United States. CA Cancer J Clin. 2018;68(1):31-54. https://doi.org/10.3322/caac.21440.

22. Jin M, Cai S, Guo J, Zhu Y, Li M, Yu Y, et al. Alcohol drinking and all cancer mortality: a meta-analysis. Ann Oncol. 2013;24(3):807-16. https://doi.org/10.1 093/annonc/mds508.

23. McTiernan A, Friedenreich CM, Katzmarzyk PT, Powell KE, Macko R, Buchner $D$, et al. Physical activity in cancer prevention and survival: a systematic review. Med Sci Sports Exerc. 2019;51(6):1252-61. https://doi.org/10.1249/ MSS.0000000000001937.

24. Li Y, Cai S, Ling Y, Mi S, Fan C, Zhong Y, et al. Association between total sleep time and all cancer mortality: non-linear dose-response meta-analysis of cohort studies. Sleep Med. 2019;60:211-8. https://doi.org/10.1016/j.sleep.2 019.03.026.

25. Veronese N, Li Y, Manson JE, Willett WC, Fontana L, Hu FB. Combined associations of body weight and lifestyle factors with all cause and cause specific mortality in men and women: prospective cohort study. BMJ. 2016; 355:15855.

26. Tollosa DN, Tavener M, Hure A, James EL. Adherence to multiple health behaviours in cancer survivors: a systematic review and meta-analysis. J Cancer Surviv. 2019;13(3):327-43. https://doi.org/10.1007/s11764-01900754-0.

27. SCHOENFELD D. Partial residuals for the proportional hazards regression model. Biometrika. 1982;69(1):239-41. https://doi.org/10.1093/biomet/ 69.1.239.

28. Arias E, Xu J, Kochanek KD. United States Life Tables, 2016. Natl Vital Stat Rep. 2019;68(4):1-66.

29. Shahab L, McGowan JA, Waller J, Smith SG. Prevalence of beliefs about actual and mythical causes of cancer and their association with sociodemographic and health-related characteristics: Findings from a crosssectional survey in England. Eur J Cancer. 2018;103:308-16. https://doi.org/1 0.1016/j.ejca.2018.03.029.

30. Lv J, Liu Q, Ren Y, Gong T, Wang S, Li L. Socio-demographic association of multiple modifiable lifestyle risk factors and their clustering in a representative urban population of adults: a cross-sectional study in Hangzhou, China. Int J Behav Nutr Phys Act. 2011;8(1):40. https://doi.org/1 0.1186/1479-5868-8-40.

31. Stenholm S, Head J, Kivimaki M, Kawachi I, Aalto V, Zins M, et al. Smoking, physical inactivity and obesity as predictors of healthy and disease-free life expectancy between ages 50 and 75: a multicohort study. Int J Epidemiol. 2016;45(4):1260-70. https://doi.org/10.1093/ije/dyw126.

32. Li K, Huesing A, Kaaks R. Lifestyle risk factors and residual life expectancy at age 40: a German cohort study. Bmc Med. 2014;12(1):59. https://doi.org/1 0.1186/1741-7015-12-59.

33. Flegal KM, Kit BK, Orpana H, Graubard BI. Association of all-cause mortality with overweight and obesity using standard body mass index categories: a 
systematic review and meta-analysis. JAMA. 2013;309(1):71-82. https://doi. org/10.1001/jama.2012.113905.

34. Dixon JB, Egger GJ. A narrow view of optimal weight for health generates the obesity paradox. Am J Clin Nutr. 2014;99(5):969-70. https://doi.org/10.3 945/ajcn.114.086470

35. Meyerhardt JA, Kroenke CH, Prado CM, Kwan ML, Castillo A, Weltzien E, et al. Association of weight change after colorectal cancer diagnosis and outcomes in the Kaiser Permanente Northern California Population. Cancer Epidemiol Biomarkers Prev. 2017;26(1):30-7. https://doi.org/10.1158/10559965.EPI-16-0145.

36. Strulov Shachar S, Williams GR. The obesity paradox in cancer-moving beyond BMI. Cancer Epidemiol Biomarkers Prev. 2017;26(1):13-6. https://doi. org/10.1158/1055-9965.EPI-16-0439

37. Kim Y, Je Y, Giovannucci EL. Association between alcohol consumption and survival in colorectal cancer: a meta-analysis. Cancer Epidemiol Biomarkers Prev. 2019;28(11):1891-901. https://doi.org/10.1158/1055-9965.EPI-19-0156.

38. World Health Organization. Global status report on alcohol and health 2018 Geneva: World Health Organization; 2018.

\section{Publisher's Note}

Springer Nature remains neutral with regard to jurisdictional claims in published maps and institutional affiliations.

Ready to submit your research? Choose BMC and benefit from:

- fast, convenient online submission

- thorough peer review by experienced researchers in your field

- rapid publication on acceptance

- support for research data, including large and complex data types

- gold Open Access which fosters wider collaboration and increased citations

- maximum visibility for your research: over $100 \mathrm{M}$ website views per year

At BMC, research is always in progress.

Learn more biomedcentral.com/submissions 